\title{
Pre-delivery hypotension after spinal anesthesia during cesarean section and its associated factors at Jigme Dorji Wangchuck National Referral Hospital, Bhutan
}

\author{
Tenzin Yoezer ${ }^{1}$, Karma Tenzin², Jampel Tshering ${ }^{3}$, Yin M Than ${ }^{4}$, Kuenza P Wangmo \\ ${ }^{1,2}$ Faculty of Postgraduate Medicine, Khesar Gyalpo University of Medical Sciences of Bhutan, Thimphu, Bhutan \\ ${ }^{3-5}$ Department of Anesthesiology, Jigme Dorji Wangchuck National Referral Hospital, Thimphu, Bhutan
}

\begin{abstract}
Introduction: The current choice of anesthesia for the cesarean section is spinal anesthesia. However, hypotension is the major complication. If promptly not recognized and treated, it increases the morbidity and mortality of the mother and fetus. This study was conducted to evaluate the rate of pre-delivery hypotension and risk factors following spinal anesthesia for cesarean section at the National Referral Hospital in Bhutan. Methods: A cohort study was conducted from $1^{\text {st }}$ October 2018 to $30^{\text {th }}$ June 2019 on 350 women undergoing cesarean section under spinal anesthesia. Pre-delivery hypotension was defined as systolic blood pressure $<100 \mathrm{~mm} \mathrm{Hg}$. The association of factors for hypotension was tested using multivariable binary logistic regression using a forward stepwise model. A $p$-value $<0.05$ was considered significant. Results: The rate of pre-delivery hypotension was 74.6 $\%(n=261)$. History of hypertension during pregnancy (Adjusted OR $0.25,[0.11-0.60], p=0.013)$, prophylaxis use of ephedrine (Adjusted OR 0.45, [0.22-0.92], $p=0.024$ ) and ondansetron (Adjusted OR 0.43, [0.22-0.82], $p=0.010$ ), longer preoperative fasting duration (Adjusted OR 1.12, [1.01-1.21], $p=0.024$,), sensory block level $\leq$ T4 (Adjusted OR 3.4, [1.8-6.4], $p=<0.001$ ) and baseline systolic blood pressure $\leq 120 \mathrm{mmHg}$ (Adjusted OR 2.8, [1.5-5.1], $p=0.001$ ) were significant risk factors. Conclusions: This study conduces that the rate of pre-delivery hypotension following spinal anesthesia in a cesarean section was high among women undergoing cesarean section. It is alarming as around two-third of women and fetus undergoing cesarean section under spinal anesthesia are at risk of consequences of hypotension. Most of the risk factors in the study are modifiable. The study suggests that if the anesthesia provider intervenes in managing the modifiable risk factors and treat hypotension promptly, it can help reduce the risk of women and fetus to spinal hypotension consequences.
\end{abstract}

Keywords: Cesarean section; Ephedrine; Ondansetron; Pre-delivery hypotension; Spinal anesthesia.

\section{INTRODUCTION}

Currently, worldwide, spinal anesthesia has become a preferred anesthetic technique for both elective and emergency cesarean section ${ }^{1}$. However, spinal anesthesia is associated with hypotension with an incidence of $70-80 \%$ without pharmacological prophylaxis ${ }^{2}$. Hypotension developed after administration of intra-thecal local anesthesia till delivery of the fetus is defined as predelivery hypotension. It is the period where both the fetus and mother are at the highest risk. Hypotension following spinal anesthesia is due to sympathetic blockade by the local anesthetic ${ }^{3}$. It is further exacerbated by aorto-caval compression by the gravid uterus when the woman lies in a supine position and by the dose of local anesthetics ${ }^{4}$. The optimal dosage of local anesthetics for a pregnant woman is variable due to woman's body height ${ }^{5,6}$ weight $^{7,8}$ intra-abdominal pressure ${ }^{9}$ and lumbosacral cerebral spinal volume ${ }^{9,10}$. Spinal anesthesia is

\section{Corresponding author:}

Tenzin Yoezer

yoezer27@gmail.com performed at L4/5 or L3/4 due to easy anatomical identification and being safe from damaging the spinal cord.

Hypotension causes maternal nausea, vomiting (could lead to aspiration), chest discomfort and loss of consciousness. If severe, untreated hypotension leads to cardiac arrest and maternal death ${ }^{11}$. A confidential review into maternal deaths in South Africa in 2011-2013 reported that more than half of all anesthetic deaths were still related to spinal hypotension ${ }^{11}$. To the fetus, decreased maternal blood flow impairs placental blood flow causing neonatal acidosis, and if severe, neurological insult and intrauterine fetal death ${ }^{12,13}$. Neonates born to maternal hypotension lasting more than two minutes were associated with ischemic-perfusion injury indicated by a significant increase in plasma xanthine, serum uric acid and plasma malondialdehyde in the umbilical vein ${ }^{12}$. If hypotension was more than four minutes, neurobehavioral changes in the first four to seven days of neonatal life were observed ${ }^{13}$.

The incidence of cesarean section in Bhutan in 2019 was $23.23 \%{ }^{14}$. Although in Bhutan, there is no record of maternal and infant morbidity and mortality due to spinal hypotension, this is a big concern when a country is gearing towards achieving SDG 2030 goals. Severe hypoperfusion impairs neonate's neurological 
development. It will increase the country's disability and nonworking population group ${ }^{15}$. For a developing country like Bhutan, it will increase the country's burden.

Spinal hypotension was studied extensively over the decades. However, even today, this remains unsolved. It is currently the most talked-about in obstetric anesthesia. The majority of the previous studies have focused on the spinal hypotension developed throughout the surgery. Spinal hypotension was studied extensively over the decades. However, even today, this remains unsolved. It is currently the most talkedabout in obstetric anesthesia. The majority of previous studies have studied the rate of intraoperative hypotension. The rate of predelivery hypotension and its associated risk factors are not much studied. However, the rate of intraoperative hypotension after the delivery of the fetus will be masked by uterine blood loss and vasodilatory effect by oxytocin. Therefore, this study was conducted on pregnant women undergoing cesarean section under spinal anesthesia to find the rate of predelivery hypotension based on the inclusion and exclusion criteria. American Society of Anesthesiology (ASA) classification is one of the widely used preoperative scores by the anesthesia provider. It helps predict patient's operative risk (postoperative mortality and morbidity) based on their physiological status.16 ASA classification has five scales. The high ASA classification has the highest operative risk. The secondary objective was to identify the risk factors associated with predelivery hypotension.

\section{METHODS}

This was a hospital-based cohort study among the women coming to Jigme Dorji Wangchuck National Referral Hospital (JDWNRH) for caesarean delivery under spinal anaesthesia from $01^{\text {st }}$ October 2018 to $30^{\text {th }}$ June 2019 . The study was approved by Research Ethics Board of Health vide approval number REBH/ Approval/2018/054 dated $3^{\text {rd }}$ September 2018.

The study included 350 pregnant women undergoing caesarean section under spinal anaesthesia who were American Society of Anaesthesiology (ASA) classification II and gestation above 35 weeks. Women coming to cesarean section were selected through systematic random sampling. The first patient was selected through lucky dip from the operating list. Details about patient selection is shown in Figure 1. Exclusion criteria were:

- ASA more than III

- Absolute or relative contraindication for spinal anesthesia

- Baseline systolic blood pressure less than $100 \mathrm{~mm} \mathrm{Hg}$

- Those who are converted to general anesthesia

Women undergoing cesarean delivery in this study received spinal anesthesia as per the standard operating procedure of the department. No procedure or management modification was done for this study. Due to the limited number of anesthesiologists in the country, certified nurse anesthesia placed spinal anesthesia without supervision. Anesthesiologists are called if needed.
All the anesthetists in our setting take an average of two consecutive non-invasive systolic blood pressures measured just before induction of spinal anesthesia as a baseline. After spinal anesthesia was administered, blood pressures were monitored every three minutes until the baby was delivered. IV fluid preloading, prophylactic vasopressor and left lateral position were at the discretion of attending anaesthetist.

A self-designed pro forma was used for data collection. It was reviewed by a panel of anaesthesiologists and obstetricians and pretested in 20 women undergoing caesarean section prior to data collection period. The data were collected by the anaesthesia assistant and information was not shared with the attending anaesthetist. The variables collected included age, weight, height, gravidity, type of caesarean section, previous caesarean section and history of hypertension before the anaesthesia procedure. Preoperative fasting duration was asked from the patient in the operation theatre. We also recorded variables related to spinal anaesthesia such as the amount and type of preloading and coloading fluid, spinal drugs, prophylaxis drugs, patient and table position, sensory level and neonate's birthweight. The most commonly used definition of hypotension in the studies is systolic blood pressure less than $100 \mathrm{mmHg}$ or $>20 \%$ of baseline systolic ${ }^{17}$. Thus, the same definition was used in this study. In JDWNRH all the attending anesthetists treat when systolic blood pressure is $<100 \mathrm{mmHg}$.

Data were entered and validated in Epi Data 3.1 (Odense, Denmark). Data analysis was done in a version of IBM SPSS Version 22.0. Descriptive data are expressed in terms of percentages, ratios, mean and median. The outcome variable was defined as spinal hypotension (yes/no) if systolic blood pressure was less than $100 \mathrm{mmHg}$. The Chi-square test was used for categorical and unpaired t-test for the continuous data. The association of factors for hypotension was tested using multivariable binary logistic regression using a forward stepwise model. The results were reported as an adjusted odds ratio with $p$-value and $95 \%$ confidence interval. A $p$-value $<0.05$ was taken as statistically significant.

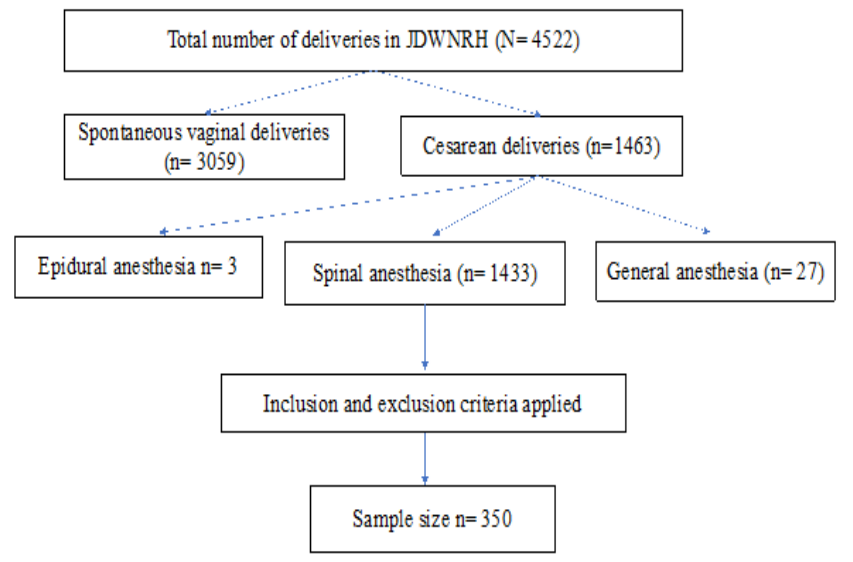

Figure 1. Flow chart showing selection of women undergoing spinal anesthesia for the study 


\section{RESULTS}

\section{Basic characteristics}

Three hundred and fifty women underwent cesarean section under spinal anesthesia at JDWNRH, Bhutan. Hypotension was developed by 261 women (74.6\%) after spinal anesthesia.
The mean time of onset of the first episode of hypotension was 5.3 minutes \pm 3.1 (minimum in 1 minute and maximum in 20 minutes).

The mean age $( \pm \mathrm{SD})$ of the mothers was $29 \pm 5$ years with the youngest being 18 years old and the eldest being 43 years old. The mean height $( \pm \mathrm{SD})$ was $154 \pm 6 \mathrm{~cm}$ with the shortest

Table 1. Basic characteristic of women undergoing cesarean section under spinal anesthesia at National Referral Hospital in Bhutan, $1^{\text {st }}$ October $2018-3^{\text {th }}$ June 2019

\begin{tabular}{|c|c|c|c|c|}
\hline \multirow[t]{2}{*}{ Basic characteristics } & \multirow{2}{*}{$\begin{array}{c}\text { Total } \\
n(\%)\end{array}$} & \multicolumn{2}{|c|}{ Pre-delivery Hypotension } & \multirow[t]{2}{*}{$p$-value* } \\
\hline & & No $(\%)$ & Yes $(\%)$ & \\
\hline \multicolumn{5}{|l|}{ Age (year) } \\
\hline$\leq 35$ & $307(87.7)$ & $76(24.8)$ & $231(75.2)$ & 0.558 \\
\hline$>35$ & $43(12.3)$ & $13(30.2)$ & $30(69.8)$ & \\
\hline \multicolumn{5}{|l|}{ Weight gain $(\mathrm{kg}) n=228$} \\
\hline$\leq 10$ & $185(52.9)$ & $44(23.8)$ & $141(76.2)$ & 0.532 \\
\hline$>10$ & $165(47.1)$ & $45(27.3)$ & $120(72.7)$ & \\
\hline \multicolumn{5}{|l|}{ BMI (kg/m2) } \\
\hline$\leq 25$ & $51(14.6)$ & $13(25.5)$ & $38(74.5)$ & 1.00 \\
\hline$>25$ & $299(85.4)$ & $76(25.4)$ & $33(84.6)$ & \\
\hline \multicolumn{5}{|l|}{ Height $(\mathrm{cm}) \quad n=344$} \\
\hline$\leq 150$ & $87(25.3)$ & $23(26.4)$ & $64(73.6)$ & 1.00 \\
\hline$>150$ & $257(74.7)$ & $66(25.7)$ & $191(74.3)$ & \\
\hline \multicolumn{5}{|l|}{ Surgery type } \\
\hline Elective & $194(55.4)$ & $39(20.1)$ & $155(79.9)$ & 0.015 \\
\hline Emergency & $156(44.6)$ & $50(32.1)$ & $106(67.9)$ & \\
\hline \multicolumn{5}{|l|}{ Pregnancy } \\
\hline Singleton & $346(98.9)$ & $88(25.4)$ & $258(74.6)$ & 1.00 \\
\hline Twins & $4(1.1)$ & $1(25)$ & $3(75)$ & \\
\hline Previous cesarean section & $166(47.4)$ & $34(20.5)$ & 132(79.5) & 0.04 \\
\hline Hypertension in pregnancy & $32(9.1)$ & $14(43.8)$ & $18(56.2)$ & 0.022 \\
\hline \multicolumn{5}{|l|}{ Antihypertensive drugs $n=32$} \\
\hline Methyldopa & $24(75.0)$ & $9(37.5)$ & $15(62.5)$ & 0.188 \\
\hline Nifedipine & $1(3.1)$ & $0(0.0)$ & $1(100.0)$ & \\
\hline Hydralazine & $7(21.9)$ & $5(71.4)$ & $2(28.6)$ & \\
\hline \multicolumn{5}{|l|}{ Gravidity } \\
\hline 1 & $95(27.1)$ & $27(28.4)$ & $68(71.6)$ & 0.872 \\
\hline 2 & $171(48.9)$ & $39(22.8)$ & $132(77.2)$ & \\
\hline 3 & $55(15.8)$ & $15(27.3)$ & $40(72.7)$ & \\
\hline 4 & $18(5.1)$ & $5(27.8)$ & $13(72.2)$ & \\
\hline$\geq 5$ & $11(3.1)$ & $3(27.3)$ & $8(72.7)$ & \\
\hline \multicolumn{5}{|l|}{ Birthweight in gram } \\
\hline$\leq 4000$ & $324(92.6)$ & $86(26.5)$ & $238(73.5)$ & 0.105 \\
\hline$>4000$ & $26(7.4)$ & $3(11.5)$ & $23(88.5)$ & \\
\hline \multicolumn{5}{|l|}{ Baseline systolic BP (mmHg) } \\
\hline$\leq 120$ & $157(44.9)$ & $25(15.9)$ & $132(84.1)$ & $<0.001$ \\
\hline$>120$ & $193(55.1)$ & $64(33.2)$ & $129(66.8)$ & \\
\hline \multicolumn{5}{|l|}{ Baseline heart rate (bpm) } \\
\hline$\leq 100$ & $94(26.9)$ & $19(20.2)$ & $75(79.8)$ & 0.223 \\
\hline \multirow[t]{2}{*}{$>100$} & $256(73.1)$ & $70(27.3)$ & $186(72.7)$ & \\
\hline & & $n$ (mean, SD) & $n$ (mean, SD) & \\
\hline Fasting duration(hour) & 323 & $84(9 \pm 3)$ & $239(10 \pm 3)$ & $<0.001$ \\
\hline
\end{tabular}

*A p-value less than 0.05 (or $\leq 0.05$ ) is statically significant. 
Table 2. Description of anesthesia technique of women undergoing cesarean section under spinal anesthesia at National Referral Hospital in Bhutan, $1^{\text {st }}$ October $2018-3^{\text {th }}$ June 2019

\begin{tabular}{|c|c|c|c|c|}
\hline \multirow[t]{2}{*}{ Basic characteristics } & \multirow{2}{*}{$\begin{array}{l}\text { Total } \\
n(\%)\end{array}$} & \multicolumn{2}{|c|}{ Pre-delivery Hypotension } & \multirow[t]{2}{*}{$p$-value* } \\
\hline & & $n(\%)$ & Yes $(\%)$ & \\
\hline \multicolumn{5}{|l|}{ Medication } \\
\hline a) Ephedrine & $80(22.9)$ & $50(62.5)$ & $30(37.5)$ & 0.007 \\
\hline b) Phenylephrine & $2(0.6)$ & $1(50.0)$ & $1(50.0)$ & 1.00 \\
\hline c) Ondansetron & $169(48.3)$ & $110(65.1)$ & $59(34.9)$ & $<\mathbf{0 . 0 0 1}$ \\
\hline Preloading IV fluid & $329(94.0)$ & $86(26.1)$ & 243(73.9) & 0.342 \\
\hline \multicolumn{5}{|c|}{ Amount of IV preloading given (mL) $n=329$} \\
\hline$\leq 300$ & $212(60.6)$ & 195(91.98) & $17(8.02)$ & 0.325 \\
\hline$>300$ & $117(33.4)$ & $111(94.9)$ & $6(5.1)$ & \\
\hline \multicolumn{5}{|c|}{ Time duration IV preloading given(min) $n=329$} \\
\hline$\leq 5$ & $107(32.5)$ & $36(33.6)$ & $71(66.4)$ & 0.044 \\
\hline$>5$ & $222(67.5)$ & $50(22.5)$ & $172(77.5)$ & \\
\hline $\begin{array}{l}\text { Sitting position for } 5 \text { minutes after } \\
\text { intrathecal injection }\end{array}$ & $7(2.0)$ & $1(14.3)$ & $6(85.7)$ & 1.00 \\
\hline Leg wrapping & $2(0.6)$ & $2(100.0)$ & $0(0.00)$ & 0.684 \\
\hline Wedge of $15 \mathrm{~cm}$ under right hip & $2(0.6)$ & $2(100.0)$ & $0(0.00)$ & 1.00 \\
\hline Left lateral table tilt & $33(9.4)$ & $11(33.3)$ & $22(66.7)$ & 0.376 \\
\hline \multicolumn{5}{|l|}{ Level of spinal block } \\
\hline T3-4 & $142(40.6)$ & $20(14.1)$ & $122(85.9)$ & $<\mathbf{0 . 0 0 1}$ \\
\hline $\mathrm{T} 5-7$ & $208(59.4)$ & $69(33.2)$ & $139(66.8)$ & \\
\hline
\end{tabular}

$S D$ - standard deviation.

*A p-value less than 0.05 (or $\leq 0.05$ ) is statically significant.

being $131 \mathrm{~cm}$ and the tallest being $179 \mathrm{~cm}$. There was incomplete data from height $(n=122)$ and weight $(n=6)$.

During the pre-anesthesia checkup, 346 (98.9\%) were singleton pregnancy and $32(9.1 \%)$ had hypertension. The mean preoperative fasting duration for both elective and emergency surgeries was $9 \pm 4$ hours (minimum 4 hours and maximum 20 hours). The mean preoperative fasting duration in elective and emergency was 13 hours and 7.5 hours, respectively. There were no serious adverse events to the mother like high spinal block and loss of consciousness needing intubation, intensive-care unit (ICU) admission, cardiac arrest or maternal death. Table 1 shows the basic characteristics of the description of parturient.

\section{Anesthesia characteristics}

Crystalloid IV fluid was used for both preloading and co-loading and no colloid was infused. The mean $( \pm$ SD) preloading and co-loading fluid infused was $308 \pm 19 \mathrm{~mL}$ and $387 \pm 181 \mathrm{~mL}$, respectively.

Only seven (2\%) patients were kept sitting for five minutes after the injection of local anesthesia to spinal space. Non-pharmacological methods like leg wrapping $2(0.6 \%)$, putting a wedge of $15 \mathrm{~cm}$ under the right hip 2(0.6\%), left lateral table tilt $33(9.4 \%)$ were not common practice. No attending anesthetist had performed manual uterine displacement. Neonate was delivered on average $10 \pm 4$ minutes after anesthesia was administered. Table 2 shows the detailed description of anesthetic techniques.

\section{Risk and protective factors}

Spinal sensory level $\leq \mathrm{T} 4$ increased the odds of spinal hypotension by 3.404 times (AOR $3.40,95 \%$ CI $1.78-6.44$ ). Similarly, the longer preoperative fasting duration and baseline systolic blood pressure $\leq 120 \mathrm{mmHg}$ increased the odds of spinal hypotension

Table 3. Factors associated with hypotension after spinal anesthesia among women undergoing cesarean section at National Referral Hospital in Bhutan, $1^{\text {st }}$ October 2018 - $30^{\text {th }}$ June 2019

\begin{tabular}{|c|c|c|c|}
\hline Variable & AOR* & $95 \% \mathrm{CI} \dagger$ & $p$-value \\
\hline $\begin{array}{l}\text { Hypertension in } \\
\text { pregnancy }(\mathrm{Ref}=\mathrm{No})\end{array}$ & 0.32 & $0.13-0.78$ & 0.01 \\
\hline $\begin{array}{l}\text { Fasting duration (hour) } \\
\text { (Ref= no fasting) }\end{array}$ & 1.11 & $1.01-1.21$ & 0.02 \\
\hline $\begin{array}{l}\text { Ephedrine prophylaxis } \\
(\mathrm{Ref}=\mathrm{No})\end{array}$ & 0.45 & $0.22-0.92$ & 0.03 \\
\hline $\begin{array}{l}\text { Ondansetron prophylaxis } \\
(\mathrm{Ref}=\mathrm{No})\end{array}$ & 0.43 & $0.22-0.82$ & 0.01 \\
\hline $\begin{array}{l}\text { Level of spinal block } \\
\text { T3-4 (Ref }=<\mathrm{T} 4)\end{array}$ & 3.40 & $1.80-6.44$ & $<0.001$ \\
\hline $\begin{array}{l}\text { Baseline systolic } \mathrm{BP} \leq \\
120 \mathrm{mmHg}(\text { Ref }=>120 \\
\mathrm{mmHg})\end{array}$ & 2.76 & $1.49-5.09$ & 0.001 \\
\hline
\end{tabular}


by 1.11 (AOR 1.11, 95\% CI $1.01-1.21$ ) and 2.76 (AOR 2.76, 95\% CI 1.49 - 5.09) times, respectively. Hypertension during pregnancy was a protective factor for the development of hypotension (AOR 0.32, 95\% CI 0.13-0.78). Similarly, the use of ephedrine (AOR 0.45, 95\% CI 0.22 - 0.92) and ondansetron (AOR $0.43,95 \%$ CI $0.22-0.82$ ) as prophylaxis decreased the incidence of hypotension as shown in Table 3.

\section{DISCUSSION}

\section{Rate of hypotension}

The pre-delivery hypotension rate in this study was $74.6 \%$ $(n=261)$, higher than as reported by Anusorntanawat ${ }^{18}$ and Knigin et $\mathrm{al}^{19}$. The higher rate of predelivery hypotension in this study could be due to the differences in definition. Anusorntanawat defined hypotension as systolic blood pressure $<90 \mathrm{~mm} \mathrm{Hg}$ whereas we defined hypotension as systolic blood pressure $<100$ mm Hg. A similar outcome was observed by Klohr et al with even minor differences in definition leading to significant differences in the incidence of hypotension ${ }^{17}$. The predelivery hypotension per se is not studied much and is limited in the literature. With the use of oxytocin and blood loss from the uterus incision, the rate of hypotension cannot be compared with predelivery hypotension. The vasodilatory effect of oxytocin and blood loss will decrease blood pressure further. The degree of blood pressure drop will depend on the rate of oxytocin and the amount of blood loss.

The other reason for a higher rate of hypotension in this study could be due to less use of pharmacological prophylactics (ephedrine was used by $22.9 \%$, phenylephrine $0.6 \%$, ondansetron $48.3 \%$ ). Without pharmacological prophylaxis, the rate of hypotension in our study was comparable to the report by Mercier et $\mathrm{al}^{2}$. Similarly, the use of non-pharmacological methods like leg wrapping, table tilt and wedge under the hip was less in our study. These methods alleviate compression of inferior vena cava by gravid uterus and pooling of blood in lower limbs. Hassanain et al observed the changing the position from supine to left lateral position increased cardiac output and heart rate ${ }^{20}$. Kundra et al also observed that the maternal blood flow velocities and wave increases when full-term women were placed in left lateral tilt position $^{21}$. Similarly, leg elevation ${ }^{22}$ and compression ${ }^{23}$ in clinical trials showed a reduced incidence of hypotension. However, the Cochrane database review showed inconclusive results about the effectiveness of non-pharmacological methods ${ }^{24}$.

Almustafa et al have reported that variation in 32 adrenoreceptors ( $(32 \mathrm{AR})$ behaved differently in developing spinal hypotension and the requirement of vasopressors. The $32 \mathrm{AR}$ genotype Gly16 and Glu27 had a higher incidence of hypotension and vasopressor requirement than homozygous Arg16 and Gln27 ${ }^{25}$. Though no genetic study was done in this study, there is a possibility of $32 \mathrm{AR}$ genetic variation in the Bhutanese population looking at the high rate of predelivery hypotension. Future genetic study on $32 \mathrm{AR}$ is needed to confirm the role of $32 \mathrm{AR}$ in Bhutanese mothers in developing spinal hypotension after spinal anesthesia.
From this study, we found three significant associated risk factors and three protective factors. The risk factors that increase hypotension after spinal anesthesia in cesarean sections were longer preoperative fasting, neuraxial level $\leq \mathrm{T} 4$ and baseline systolic blood pressure $\leq 120 \mathrm{mmHg}$. The protective factors were hypertensive disorder during pregnancy, ephedrine and ondansetron used as prophylaxis.

\section{Risk factors}

Women who have fasted longer hours were found to be 1.11 times the odds of getting hypotension (1.01-1.21, p-value 0.02$)$. To our knowledge, this was the first study to show longer preoperative fasting hours being associated with hypotension in women undergoing cesarean section under spinal anesthesia. Longer preoperative fasting was linked with thirst, hunger, dehydration, hypovolemia and nausea ${ }^{26}$. Fasting also leads to generalized stress and increases sympathetic activity. High baseline sympathetic activity was associated with spinal hypotension ${ }^{27}$. In our setting, we have one operation room fully dedicated to the cesarean section for both elective and emergency cesareans. Women scheduled for elective cesarean sections have fasted longer than 13 hours. This was because emergency cesareans were performed in between the elective cesarean sections. The surgeon and anesthetist should plan accordingly to reduce the fasting hours in the elective cesareans.

Spinal block level $\leq \mathrm{T} 4$ has 3.40 times the odds of developing hypotension than spinal block level >T4 (1.80$6.44, p$-value $<0.001)$. The results of the present study agree with previous studies ${ }^{28,29}$. Among many factors, variability of lumbosacral cerebrospinal fluid could be the most important factor which affects the spread of local anesthesia ${ }^{10}$. Patient's height $^{5,6,10}$ obesity $^{7}$ and intra-abdominal pressure ${ }^{10}$ influences the lumbosacral cerebrospinal fluid volume. Another factor that influences the spread of anesthesia is the position and baricity of local anesthesia ${ }^{30}$. Measures to avoid high spinal block are low dose local anesthesia ${ }^{31}$, adjusting the dose of bupivacaine according to the patients height ${ }^{5,6}$ and $\mathrm{BMI}^{8,31}$, slow injection of local anesthesia ${ }^{28}$, administering local anesthesia in sitting position $^{32}$ and isobaric local anesthesia ${ }^{30}$.

The odds of developing hypotension when baseline systolic blood pressure $\leq 120 \mathrm{mmHg}$ was $2.76(1.49-5.09$, $p$-value $0.001)$. This is in agreement with previous studies although, the exact mechanism is not known ${ }^{33}$. Giving prophylaxis vasopressor ${ }^{2,29}$, adequate pre-loading and co-loading, rigorous monitoring may prevent hypotension in this situation.

\section{Protective factors}

Women who were diagnosed with the hypertensive disorder during the pregnancy had 0.32 odds $(0.13-0.78, p$-value 0.01$)$ of developing hypotension. The risk of getting hypotension was reduced by $68 \%$ as compared to normal women. Similar to our study, Nikooseresht $M$ et al found preeclamptic patients had significantly lower spinal hypotension than healthy women $(17 \%$ 
vs 53\%) $)^{34}$. Similarly, Sivevski A et al have reported low incidence and severity of spinal hypotension in pre-eclamptic patients $(25 \%$ vs $53 \%)^{35}$. The possible reason for this could be carrying a small fetus for gestational age due to restricted fetal growth and less aortocaval compression ${ }^{34}$. Moreover, pre-eclamptic patients have increased sympathetic activity (increased synthesis of potent vasopressor) and systemic vascular resistance secondary to defect in vascular endothelium during trophoblast development ${ }^{36}$.

Prophylactic administration of $6 \mathrm{mg}$ ephedrine intravenous bolus had a lower incidence of spinal predelivery hypotension than those who had not received in women undergoing cesarean section. The finding in this study is comparable with the result of Shiteman et $\mathrm{al}^{37}$. However, Sigh et al reported $5 \mathrm{mg}$ intravenous ephedrine used as prophylactic did not significantly reduce the incidence of hypotension than control $(60 \% \text { vs } 72 \%)^{38}$. Recent studies have reported ephedrine crosses the placenta, acts on fetus $\beta 2$ receptors and increases fetus metabolism ${ }^{2,29}$. In this study, ephedrine was used more frequently than phenylephrine due to availability. However, we do not have data for the fetal outcome following ephedrine use.

Ondansetron is a 5HT3 receptor antagonist. The 5-HT3 receptor present in the heart chamber is responsible for Bezold Jarisch (BJZ) reflex in response to volume depletion. Blocking the 5-HT3 receptor attenuates the BJZ reflex and prevents hypotension $^{39}$. Previous studies have shown prophylactic intravenous ondansetron decreases hypotension, the requirement of ephedrine and shivering ${ }^{39,40}$. Similar to the previous studies, this study also found prophylactic use of $4 \mathrm{mg}$ ondansetron before spinal anesthesia decreases the rate of hypotension.

\section{Strength of the study}

This study has a fairly adequate sample size. Around two-thirds $(62 \%)$ of deliveries under cesarean section in Bhutan happens in JDWNRH which includes $50 \%$ women from Thimphu (capital city) and 50\% from other parts of Bhutan being referred to JDWNRH ${ }^{14}$. Although the study was not designed to be representative of the whole country, the sample size was split between Thimphu residents and those from outside the city. The study also included a thorough list of possible maternal and anesthetic risk factors through a rigorous literature search. The study also has included the practice of pharmacological and nonpharmacological prophylaxis which in previous studies have not included. Also, the study included both emergency and elective cesarean sections.

\section{LIMITATIONS}

Data were collected only up to the delivery of the neonate. Therefore, this study has no data on estimated surgical blood loss, hypotension developed after the delivery of a baby and adverse outcomes of mother and neonate. We have not standardized the dose of local anesthesia, which is also an important factor of spinal hypotension. Also, this study does not have data on the indication for the cesarean section.

\section{CONCLUSIONS}

The rate of pre-delivery hypotension in the study was high. Most of the significant risk factors identified from the research are modifiable. Reducing preoperative fasting duration, using ondansetron and ephedrine as prophylaxis will decrease the hypotension. The knowledge and skill of an anesthetist are a key in reducing hypotension and its consequences to the mother and infant.

\section{ACKNOWLEDGEMENTS}

The authors thank all the participants who consented to be part of the study. We are also thankful to the faculty of postgraduate medicine of Khesar Gyalpo University of Medical Sciences, Ministry of Heath, Bhutan and Jigme Dorji Wangchuck National Referral Hospital for allowing us to conduct the study. Special thanks go to Dr. Thinley Dorji for his contribution in reviewing the article.

\section{REFERENCES}

1. Lee JE, George RB, Habib AS. Spinal-induced hypotension: Incidence, mechanisms, prophylaxis, and management: Summarizing 20 years of research. Best Practice \& Research Clinical Anaesthesiology. 2017;31(1):57-68. [Full Text | DOI]

2. Mercier FJ, Augè M, Hoffmann C, Fischer C, Le Gouez A. Maternal hypotension during spinal anesthesia for caesarean delivery. Minerva Anestesiologica. 2013 Jan;79(1):62-73. [PubMed | Full Text]

3. Reiz S. Pathophysiology of Hypotension Induced by Spinal/ Epidural Analgesia. New Aspects in Regional Anesthesia 4. Berlin, Springer. 1986;176:53-5. [Full Text]

4. Kinsella SM, Lohmann G. Supine hypotensive syndrome. Obstetrics and Gynecology. 1994;83(5):774-88. [PubMed]

5. She YJ, Zheng X, Zhao BS, Zeng MT, Tan YH, Song XR. Body height and the spread of spinal anaesthesia for caesarean section: a prospective controlled trial. Acta Anaesthesiologica Scandinavica. 2017;61(7):824-31. [Full Text | DOI]

6. Yu X, Zhang F. The effect of parturient height on the median effective dose of intrathecally administered ropivacaine. Annals of Saudi Medicine. 2016 Sep 1;36(5):328-33. [PubMed | Full Text | DOI]

7. Wang HZ, Chen HW, Fan YT, Jing YL, Song XR, She YJ. Relationship between body mass index and spread of spinal anesthsia in pregnant women: A randomized controlled trial. Medical Science Monitor. 2018 Sep 4;24:6144-50. [PubMed | DOI] 
8. Jayachandran CG, Morris LJ. Correlative Study between Body Mass Index and Hypotension in Obese Patients Undergoing Cesarean Section under Spinal Anaesthesia. International Journal of Scientific Study. 2017;63(4):63. [Full Text | DOI]

9. Ni TT, Zhou Y, Yong AC, Wang L, Zhou QH. Intraabdominal pressure, vertebral column length, and spread of spinal anesthesia in parturients undergoing cesarean section: An observational study. PLoS ONE. 2018 Apr 1;13(4). [PubMed | Full Text | DOI]

10. Carpenter RL, Hogan QH, Liu SS, Crane B, Moore J. Lumbosacral cerebrospinal fluid volume is the primary determinant of sensory block extent and duration during spinal anesthesia. Anesthesiology. 1998 Jul 1;89(1):24-9. [Full Text]

11. National commitee for confidential enquiry into maternal deaths. Saving Mothers 2014-2016: Seventh report on the Confidential Enquiries into Maternal Deaths in South Africa Short Report. 2018. 1-139p. [Full Text]

12. Okudaira S, Suzuki S. Influence of spinal hypotension on fetal oxidative status during elective cesarean section in uncomplicated pregnancies. Archives of Gynecology and Obstetrics. 2005;271(4):292-5. [Full Text | DOI]

13. Corke BC, Datta S, Ostheimer GW, Weiss JB, Alper MH. Spinal anaesthesia for caesarean section: the influence of hypotension on neonatal outcome. Anesthesia. 1982 Jun; 37(6):658-62. [Full Text | DOI]

14. Ministry of Health. Annual Health Bulletin 2020. Ministry of Health: Royal Government of Bhutan. [Full Text]

15. Orser BA, Wilson CR, Rotstein AJ, Iglesias SJ, Spain BT, Ranganathan $\mathrm{P}$, et al. Improving access to safe anesthetic care in rural and remote communities in affluent countries. Anesthesia and Analgesia. 2019 Jul 1;129(1):294-300. [Full Text | DOI]

16. Mayhew D, mendonca V, Murthy BVS. A review of ASA physical status-historical perspective and modern developments. Anaesthesia. 2019 Mar; 74(3):373-9. [Full Text | DOI]

17. Klöhr S, S, Roth R, Hofmann T, Rossaint R, Heesen M. Definitions of hypotension after spinal anaesthesia for caesarean section: literature search and application to parturients. Acta Anaesthesiologica Scandinavica. 2010 Apr 23;54(8):909-21. [Full Text | DOI]

18. Ratikorn A. Incidence and Risk Factors Associated with Spinal Anesthesia Induced Predelivery Hypotension for Cesarean Section. Region 4-5 medical journal. 2015;34(4):267-79. [Full Text]

19. Knigin D, Avidan A, Weiniger CF. The effect of spinal hypotension and anesthesia-to-delivery time interval on neonatal outcomes in planned cesarean delivery. American Journal of Obstetrics and Gynecology. 2020 Nov 1;223(5):747.e1-747.e13. [Full Text | DOI]
20. Hasanin A, Soryal R, Kaddah T, Raouf SA, Abdelwahab Y, Elshafaei K, et al. Hemodynamic effects of lateral tilt before and after spinal anesthesia during cesarean delivery: An observational study. BMC Anesthesiology. 2018 Jan 15;18(1):1-9. [Full Text | DOI]

21. Kundra P, Velraj J, Amirthalingam U, Habeebullah S, Yuvaraj K, Elangovan S, et al. Effect of positioning from supine and left lateral positions to left lateral tilt on maternal blood flow velocities and waveforms in full-term parturients. Anaesthesia. 2012 Aug 1;67(8):889-93. [Full Text | DOI]

22. Hasanin A, Aiyad A, Elsakka A, Kamel A, Fouad R, Osman $\mathrm{M}$, et al. Leg elevation decreases the incidence of post-spinal hypotension in cesarean section: A randomized controlled trial. BMC Anesthesiology. 2017 Apr 24;17(1):1-6. [Full Text | DOI]

23. Elgzar WT, Said HE, Ebrahim HA. Effect of lower leg compression during cesarean section on post-spinal hypotension and neonatal hemodynamic parameters: nonrandomized controlled clinical trial. International Journal of Nursing Sciences. 2019 Jul 10;6(3):252-8. [Full Text | DOI]

24. Cluver C, Novikova N, Hofmeyr GJ, Hall DR. Maternal position during caesarean section for preventing maternal and neonatal complications. Cochrane Database of Systematic Reviews. 2013 Mar 28;2013(3):1-38. [Full Text | DOI]

25. Almustafa MM, Al-Oweidi AS, Al-Zaben KR, Qudaisat IY, Abu-Halaweh S, Alghanem SM, et al. Ephedrine requirements during spinal anesthesia for cesarean delivery in Jordanian parturients: Association with $\beta 2$ - Adrenoceptor gene variants. Annals of Saudi Medicine. 2016 Jan 1;36(1):29-36. [Full Text | DOI]

26. Tosun B, Yava A, Açikel C. Evaluating the effects of preoperative fasting and fluid limitation. International Journal of Nursing Practice. 2015;21(2):156-65. [Full Text | DOI]

27. Orbach-Zinger S, Ginosar Y, Elliston J, Fadon C, Abu-Lil M, RazA, et al. Influence of preoperative anxiety on hypotension after spinal anaesthesia in women undergoing Caesarean delivery. British Journal of Anaesthesia. 2012;109(6):943-9. [Full Text | DOI]

28. Zhang N, He L, Ni JX, Xu L. Level of sensory block after spinal anesthesia as a predictor of hypotension in parturient. Medicine (United States). 2017 Jun 1;96(25):1-6. [PubMed | Full Text | DOI]

29. Kinsella SM, Carvalho B, Dyer RA, Fernando R, McDonnell $\mathrm{N}$, Mercier FJ, et al. International consensus statement on the management of hypotension with vasopressors during caesarean section under spinal anaesthesia. Anaesthesia. 2018 Jan 1;73(1):71-92. [Full Text | DOI]

30. Atashkhoei S, Abedini N, Pourfathi H, Znoz AB, Marandi PH. Baricity of bupivacaine on maternal hemodynamics after spinal anesthesia for cesarean section: A randomized controlled trial. Iranian Journal of Medical Sciences. 2017 Mar 1;42(2):136-43. [PubMed | Full Text] 
31. Van De Velde M. Low-dose spinal anesthesia for cesarean section to prevent spinal-induced hypotension. current Opinion in Anesthesiology. 2019;32(3):268-70. [Full Text | DOI]

32. Pinto SL, Melo GAA, Barros LM, Neto NMG, Lisboa KW de SC, Gomes EB, et al. Pregnant Women Positioning in Spinal Anesthesia for Cesarean Section: Integrative Review. International Medical Society. 2017 May 13;10(179):1-8. [Full Text]

33. Atousa F, Haleh G, Zeinabsadat F, Samaneh Z. Maternal and anaesthesia-related risk factors and incidence of spinal anaesthesia-induced hypotension in elective caesarean section: A multinomial logistic regression. Indian Journal of Anesthesia. 2018 Jan 12 ;62(1):36-46. [PubMed | Full Text]

34. Nikooseresht M, Seif RMA, Hajian P, Dastaran R, Alipour N. Comparing the hemodynamic effects of spinal anesthesia in preeclamptic and healthy parturients during cesarean section. Anesthesiology and Pain Medicine. 2016 Jun 1;6(3). [PubMed | Full Text | DOI]

35. Sivevski A, Ivanov E, Karadjova D, Slaninka-Miceska M, Kikerkov I. Spinal-Induced Hypotension in Preeclamptic and Healthy Parturients Undergoing Cesarean Section. Journal of Medical Sciences. 2019;7(6):996-1000. [PubMed | Full Text | DOI]

36. Clark VA, Sharwood-Smith GH, Stewart AVG. Ephedrine requirements are reduced during spinal anaesthesia for caesarean section in preeclampsia. International Journal of Obstetric Anesthesia. 2005;14(1):9-13. [Full Text | DOI]
37. Shitemaw T, Aregawi A, Fentie F, Jemal B. Prophylactic ephedrine to prevent postspinal hypotension following spinal anesthesia in elective cesarean section: A prospective cohort study in ethiopia. Journal of Obstetric Anaesthesia and Critical Care. 2019;9(2):75. [Full Text | DOI]

38. Singh TH, Thokchom RS, Sinam M, Nongthonbam R, Devi MB, Singh KM. Prophylactic intravenous ephedrine for prevention of hypotension in cesarean section during spinal anesthesia: A comparative study. JMS - Journal of Medical Society. 2016;30(2):116-20. [Full Text | DOI]

39. Heesen M, Klimek M, Hoeks SE, Rossaint R. Prevention of Spinal Anesthesia-Induced Hypotension During Cesarean Delivery by 5-Hydroxytryptamine-3 Receptor Antagonists. Anesthesia \& Analgesia. 2016 Oct 1;123(4):977-88. [Full Text | DOI]

40. Tatikonda C, Rajappa G, Rath P, Abbas M, Madhapura V, Gopal N. Effect of intravenous ondansetron on spinal anesthesia-induced hypotension and bradycardia: A randomized controlled double-blinded study. Anesthesia: Essays and Researches. 2019;13(2):340. [PubMed | Full Text | DOI]

\section{AUTHORS CONTRIBUTION}

Following authors have made substantial contributions to the manuscript as under:

YT: Concept, design, data collection and analysis, manuscript writing and review.

KT: Design, data collection and analysis, manuscript writing and review

JT: Design, data collection and analysis, manuscript writing and review

WMT: Design, data collection and analysis, manuscript writing and review

KPW: Design, data collection and analysis, manuscript writing and review

Author agree to be accountable for all respects of the work in ensuring that questions related to the accuracy and integrity of any part of the work are appropriately investigated and resolved.

\section{CONFLICT OF INTEREST \\ None}

GRANT SUPPORT AND FINANCIAL DISCLOSURE

Ministry of Health, Royal Government of Bhutan 